\title{
3. Performance management and the performance pay paradox ${ }^{1}$
}

\begin{abstract}
Allan Hawke
Allan Hawke enjoyed a distinguished career as a senior public servant and diplomat. He was Chief of Staff to Prime Minister Paul Keating (August 1993-February 1994), Secretary of the Department of Veterans' Affairs (1994-1996), Secretary of the Department of Transport and Regional Services (1996-1999) and Secretary of the Department of Defence (1999-2002). Hawke next served as High Commissioner to New Zealand from 2003-2005 before serving as Chancellor of The Australian National University (2006-2009). Allan Hawke currently serves on the board of the Canberra Raiders NRL club.

Leaders often define themselves by the issues on which they take a stand. My seven-and-a-half years as a secretary in three departments of state spanned an era when performance-based pay became the order of the day - a fashion I resisted for the reasons outlined in this chapter. The essence of my argument is that:

- performance pay is at odds with public service culture;

- performance pay ignores the complexity of how the public service actually works;

- performance pay is bad for morale and teamwork; and

- performance pay gives senior leaders an excuse to avoid real leadership.

My experience suggests a better way to facilitate the admirable aim of a high performing organisation; this framework is set out towards the end of the paper.

During my public service, I came to appreciate the importance of rituals, symbols and words. So it may come as no surprise that I believe the term 'human resources' indicates a mindset that treats people as human capital, assets, units of production etc with inherent control connotations. The term should be outlawed in favour of the more positive notions of people and performance.
\end{abstract} 1 Paper provided by Allan Hawke to the editors in 2011 in lieu of a formal valedictory upon his retirement in
2005. It draws upon material he presented in 2001 for an SES breakfast on Defence's performance framework. 


\section{The performance pay paradox}

In my view, performance based pay experiments in the Australian Public Service have all been abject failures in the eyes of the people affected by them. Given the complexity of much of the public service, success or failure are mostly shared outcomes - that's because responsibility for meaningful bundles of work can rarely be made coincident with individual responsibility. This factor alone bedevils performance pay. Performance appraisal and pay assumptions usually include that:

- evaluation covers performance over a (normally) 12 month cycle, not just the period of recent memory;

- evaluators are consistent with one another or equilibrated through a moderation process;

- evaluators apply a consistent 'objective' standard between employees; and,

- individual employee contributions can be distinguished from the contributions of other managers and workers. ${ }^{2}$

These beliefs usually arise from the command and control school of management.

Douglas McGregor ${ }^{3}$ developed Theory X and Theory Y in the 1960s to describe what he discerned to be two very different approaches to workforce motivation. Importantly, Theory $\mathrm{X}$ and $\mathrm{Y}$ are not different ends of a continuum as commonly thought.

Based on traditional views of direction and control, Theory $\mathrm{X}$ asserts that:

- the average person has an inherent dislike of work and will avoid it if they can;

- most people must be coerced to contribute toward organisational objectives; and

- most people prefer to be directed, wish to avoid responsibility, have relatively little ambition, and want security above all.

Theory X managers see their job as being to 'motivate' their employees, believing carrots and sticks are the only effective way to get things done. Herzberg proved

2 Kohn, Alfie, 'Punished by Rewards: the trouble with gold stars, incentive plans, A's, praise and other bribes' (Boston: Houghton Mifflin Co., 1993).

3 Douglas McGregor of the MIT Sloan School of Management developed his Theory X and Theory Y explanations of human motivation in the 1960s. He is cited as creator of the 'human resources' term, influenced the way performance reviews are conducted and shaped the idea of pay for performance in the private sector. Although his theories are rarely referred to nowadays, they underpin many modern day management philosophies, including the 'hard' versus 'soft' schools. 
30 years ago that motivation is an internal construct and you can't actually motivate others to do much of anything other than what they want to do, or what they perceive to be in their self interest. ${ }^{4}$

This might be illustrated by how supervisors respond when an employee approaches them about a stuff-up. The carrot and stick school tend to shoot the messenger, assign blame and punish. So employees learn not to confess further errors, potentially leading to disastrous consequences. Those with a more positive view thank their staff for drawing attention to the problem and work with them to fix it. They get told of future problems as they emerge and have the opportunity to resolve them before things get too far out of hand.

I believe the vast majority of Australian Public Service (APS) staff would not see performance pay as being in their self interest. The rewards (even for secretaries) are relatively small, the ranking system rankles because many good performers not given the top rating think they have been short changed, and the system is not regarded as fair. Leadership and management policies and practices provide an insight into how leaders regard their employees; 'Punished by Rewards'5 argues the case against the carrot and stick approach.

Performance pay acolytes (usually in an unstated or unrecognised manner) consider that a reservoir of withheld effort must be coaxed or coerced out of people. This is the underlying premise for incentive pay programs and/or a manager's efforts to motivate and control their workforce. ${ }^{6}$

The reality is that there are not many bad people in the workplace. What's interesting is that so many executives shy away from dealing directly with poor performance and unacceptable conduct in the workplace, especially given the way those affected by these inappropriate behaviours feel about it. One might therefore expect this aspect to feature in performance pay regimes, but even there it seems to be the exception rather than the rule.

\footnotetext{
4 Herzberg, Frederick - ‘One More Time: How Do You Motivate Employees?' Harvard Business Review, September-October, 1987.

5 Scholtes, Peter R - 'Reward and Incentive Programs are Ineffective - Even Harmful' and his other articles and books, particularly 'The Leader's Handbook'.

6 During the late 1980s I was seconded to work with Tony Ayers in the Efficiency Scrutiny Unit. Each time we got 12 scrutinies together, I would sit in on a three day course with the Scrutineers called 'Managing and Consulting' run by Ross Begbie. After attending six of these courses, I was well and truly hooked on the approach and lessons. It was retitled 'Results through People' following a comment by David Block and I used that term and the course (modernised from time to time to include the latest relevant research findings) and Ross Begbie wherever I went after that to very good effect. A healthy cadre of Victor and Victoria Stone graduates are applying the lessons learnt, while Ross and his team are still teaching new people what leadership and management is all about.
} 
With the benefit of hindsight

Most APS performance based pay programs follow a three step process:

- determining the approach - what's to be done, by when and to what standard;

- the performance period - normally the calendar or financial year; and

- the performance review - the boss undertaking an 'objective' evaluation of the subordinate's performance.

Typically, evaluation involves a boss/subordinate discussion followed by the assignment of a numerical rating, sometimes with forced rankings according to the classic bell-shaped normal distribution curve. (Defence's system, by contrast, was based on incremental advancement up the pay scale, without forced rankings). The outcome usually has a remuneration implication covering pay at risk, merit pay, bonuses and judgments about contenders for promotion. Responses to 'why do it?' usually say:

- as a basis for differential pay/reward for outstanding performers;

- to provide performance feedback to individual employees;

- to identify candidates for promotion;

- to foster communication between supervisors and subordinates; and/or

- to motivate employees.

As I recall it, performance pay was introduced as a back door way of lifting remuneration for senior staff. That could not be achieved through the Industrial Relations Commission because of the very restrictive rules applying to pay increases at that time which the government had advocated to the Commission and felt bound to adhere to. It was argued that since employees contribute at different levels of effectiveness and effort, this could be recognised through introduction of a performance pay regime. The fact that that rationale no longer applies seems lost with the effluxion of time, although some departments and agencies have now done away with performance-based pay.

Nevertheless, the practice remains widespread in the APS because so many managers believe in it. They believe it works without consciously and critically analysing the assumptions behind the practice. ${ }^{7}$ And they believe in it, despite the fact that 90 per cent of managers consider the approach to be unsuccessful. ${ }^{8}$

\footnotetext{
7 'Driving Performance and Retention through Employee Engagement' by Lloyd Morgan of the Corporate Leadership Council.

8 Defence has kindly kept most of my speeches on their website - see in particular, 'People Power' address to the International Seminar of RUSI Australia on 17 November 2000; 'A Public Sector Performance Framework - the Defence Model' (which avoided the trap of relative rankings and performance pay outcomes) address to PSMPC Breakfast 18 April 2001; and "Putting People First" - keynote address to AHRI 21 August 2001.
} 
Some commentators argue that the practice continues despite evidence to the contrary because it relates to the manager's need to maintain control - or the illusion of control. Peter Scholtes, who has researched and written extensively about performance, appraisal and pay, argues that such a performance 'management' regime is inherently the wrong thing to do because three faults are common to all variations on the theme:

- it doesn't work;

- it's wrong to focus only on individuals or groups, because most opportunities for improvement involve systems, processes and technology; and

- performance 'management' is judgment, not feedback; it's a hierarchical dynamic.

Even when well intended ratings are judgmental and related to control of the person being evaluated based on the presumption that the person's inadequate contribution is separable from any systemic origin of poor performance. Where such schemes are in operation, most individuals or groups will work towards optimising their performance, regardless of its impact on the system. Creative accounting, goal displacement, withholding information, reduced quality at the expense of more output, individual visibility which discourages co-operation and other gaming strategies are the perverse results of such a perverse system. The inherent contradiction of proselytising individual performance pay assessments while simultaneously exhorting teamwork escapes the zealots.

The method, criteria and philosophy of evaluation differs between one evaluator and another. People are subjective and they are not at all objective about their subjectivity. Numerous factors affect favourable or unfavourable bias including age, family and educational background, physical appearance etc. None of these are job-related, but they do influence the outcome of performance evaluation. Where these discriminatory practices are pointed out, the people concerned deny they exist.

Performance pay can lead to patronage, subordinate sycophancy, playing and paying favourites, oiling the squeaky wheel and other inappropriate practices. Imagine the consequences if ministers wanted to be involved in the process and decisions below secretary level.

A former secretary once commented that he had assessed his SES as all being in the top five to ten per cent! Let's assume for the purpose of illustration that there is a truly unbiased performance pay system in a typical Gaussian distribution. Half of your people will learn that they are below average - a statistical inevitability. Some may accept their fate; others will view this as proof that their manager is incompetent. Some will redouble their efforts to prove the judgment and system wrong - that may be noticed, and they may be lucky 
enough to be ranked above average next time - if so, someone above average last time will fill their below average slot this time. All of this must do wonders for morale and superior workplace performance.

Then there's the case where people are told their rating by their direct supervisor before it disappears into the black box of moderation and comes out at a lower level - apart from the lack of transparency, the recipient's perception is one of unfairness and it's deeply demotivating. Those that invoke 'science' in moderating people's scores to a decimal point are kidding.

The Orwellian named 'efficiency dividend' has had particular effects on some small agencies (particularly those where most of their budget comprises staff costs), leading to very significant differences in pay rates for people doing jobs classified at the same level. The reality is that how well or badly people are paid in these circumstances often depends on how well their organisation has done in the budget bidding process. As well as the equity argument, this works against mobility and a unified APS. The Moran blueprint's analysis of what's happened since devolution of bargaining in 1997 is spot-on as are the accompanying recommendations. I think there is a compelling case to abolish performance pay and return to centralised pay fixing, perhaps under the auspices of the Australian Public Service Commission.

\section{Secretaries}

How did I rationalise these views with the performance pay regime for secretaries? In my day, the Prime Minister determined, on advice of the Remuneration Tribunal, that secretaries would be eligible for an annual 10 per cent bonus of total remuneration for superior performance, or 15 per cent for outstanding performance. Every 12 months, each secretary wrote a self assessment based on criteria which included:

- meeting government objectives;

- management;

- strategic, high quality, frank and timely advice to ministers;

- leadership; and

- professional and personal integrity and adherence to the APS Values/Code of Conduct.

Other aspects were covered from time to time, including what was being done about IT outsourcing when that ideology was popular. 
The self assessment, which formed the basis of a discussion between the secretary and portfolio minister, was copied to the Secretary of PM\&C and Public Service Commissioner. They, in turn, discussed the secretary's performance with the portfolio minister and reported to the Prime Minister who decided the outcome.

The Remuneration Tribunal's guidelines said that performance-based remuneration was not a device to provide salary supplementation to office holders and should not be applied or administered in that way. Rather, it was a way of recognising performance over and above what was reasonably expected of the office holder performing their duties competently. I could never believe that secretaries would work harder or differently just because of the possibility of an additional 10 or 15 per cent before tax.

The key question that arose in my time was whether the system of appointing and removing secretaries caused politicisation of the APS. The issue was complicated by the differential use of three and five year appointments and the implied message in who got those 'contracts'. However you answered these questions, there was the potential for a perception issue.

The portfolio minister obviously expressed satisfaction or dissatisfaction with a secretary's performance in discussion with the Secretary of PM\&C and Public Service Commissioner. One danger was the inference that the subsequent award (or non-award) of performance pay meant that the secretary had satisfied (or not) the minister's partisan political demands. In the case of the term of office, people drew conclusions about the Prime Minister's view by reference to whether the appointment was for three or five years. I argued without success to do away with performance pay and fold it into base salaries, although that did subsequently occur for secretaries when Prime Minister Rudd came to office.

The discussion on goals, priorities and the nature of the minister/secretary relationship is a very positive step, as is the annual self-assessment report from the secretary and associated interaction with the portfolio minister. Cabinet ministers were wary that their performance and judgments were also being assessed and reported to the Prime Minister by the Secretary of PM\&C and may have tailored their comments accordingly.

\section{Performance-based pay conclusion}

To sum up, I believe that performance bonuses, performance appraisal linked to pay outcomes, and other performance management schemes which involve a 'proportion of pay at risk' lead to distorted results and raise issues of equity, ratings moderation and forced distribution. I am aware of the argument that performance pay works in some organisations where rewards constitute a 
significant part of total remuneration, and where judgments about performance are based on things under the direct control of the individual being assessed and people are satisfied that the assessments and mechanisms used are fair and reasonable. None of those preconditions can be assured in the APS.

To me, a 1996 Human Resources Management article quote captures it nicely:

'From several perspectives, merit pay schemes do seem desirable; yet, in spite of this, merit pay often brings about results precisely the opposite from those desired: dissatisfaction, discouragement and decreased performance.'

I tried to influence the Management Advisory Committee's paper on performance management to no avail against the prevailing orthodoxy. Some years later the Australian National Audit Office (ANAO) carried out an audit on performance management in the APS which should have been enough to convince the diehards to abolish performance pay, but the practice continues today with the same problems and unintended consequences. The conclusion may be that most APS agency heads are still disciples of and wedded to Theory X practices.

\section{Results through people}

The great mentor, Tony Ayers, once sat patiently listening while I explained at some length why something wouldn't work. When I finished, he said 'I hear what you are against, now tell me what you are for'. It's to that end that I now turn.

'Results through people' was my credo, a refrain familiar to those in Veterans' Affairs; Transport and Regional Services; and Defence when I worked there. Eight years after serving a three year term as Secretary of Defence, the following brief overview enunciates what I stood for in terms of a performance framework and as context for what I took a stand against. My foundation belief was that people want to do a good job and make a genuine contribution - to their team, their organisation, and their nation. The leaders' task is to create an enabling culture and to facilitate that end through:

- sharpening the focus on the results that the organisation (or team) is there to achieve;

- putting in place governance processes where accountability for achieving results is clear; and

- fostering a climate where people can give their best and strive towards their potential, through regular performance feedback and support for learning. 
These three elements sound simple. Yet anyone who has tried to achieve sustained organisational improvement will know that getting them right is much harder in practice. What's hard about the first theme - focusing on results - is that even after the agency head has opened up a dialogue with the minister to clarify requirements, a lot of thinking work needs to be done by senior executives in order to translate the overall direction into specific, measurable results. That is, turning agreed high level goals into language that is comprehensible and meaningful, so that they can be absorbed, understood and acted on by staff.

Then comes the task which senior executives often underestimate - the sheer repetition of communicating the messages required so that people know what is expected of them in order to make an effective contribution. Saying it once or twice has negligible impact in my experience; by the fiftieth time when you are thoroughly sick and tired of saying it people begin to think you might just be serious about it.

What's hard about the second theme - developing robust governance processes - is that most people find 'the hot seat of accountability' an uncomfortable place to be. A proliferation of 'governance committees' is a likely consequence. Defining how responsibilities, roles and accountabilities differ between executives at each level is another very tough ask. Given the tendency to micromanage, the agency head must be vigilant to ensure that senior executives are taking a real leadership role rather than simply meddling in technical aspects of the task, for which someone in their team is actually responsible. It is, of course, vitally important to set out the contributions expected of individuals for specific and more broadly described results in such a way that people can see for themselves how what they do fits in and allows the effectiveness of their contribution to be assessed. We tried to do that through our Plan on a Page approach (see Attachment 1).

What's hard about the third theme - fostering the climate where people can give their best - is that it calls for 'soft skills', the very skills that are the hardest to get right and easiest to get wrong. People need to be properly informed of what is expected of them and how those tasks are to be performed; a necessary precondition for feedback and individual improvement. Judicious use of feedback and a commitment to support people to improve their performance and to learn are also essential elements. But most of all, there must be a willingness to be judged on the extent to which leadership rhetoric is matched by day-to-day behaviour in the workplace.

People will give you a fair day's work if they receive what they consider to be a fair day's pay. Their expectations here are principally affected by what they see other people who do similar work are getting. That's one reason why Defence's pay scales (for SES and non-SES) were transparent to everyone in the organisation. 
With the benefit of hindsight

We positioned Defence in the top quartile of APS remuneration, recognising that that position would erode over time as others increased their pay rates. That is to say, we took a broadly fair and reasonably competitive position and adjusted our position in the light of market movement each bargaining round. To complement that approach, we developed a People Leadership Framework (see Attachment 2).

Research by the Corporate Leadership Council suggests that employees stay with an organisation when they believe it is in their self interest, which they define as 'rational' commitment. This is all about financial, developmental and professional rewards. The second side of this coin is emotional commitment, which involves the extent to which employees derive pride, enjoyment, inspiration or meaning from something or someone within their organisation. Emotional commitment is regarded as more valuable in driving employee effort than rational commitment. Indeed, employees are more likely to exert discretionary effort when emotionally committed - when they believe in the value of their job, their team or their organisation. Further detail about the above issues is available in an article in the March 2003 Canberra Bulletin of Public Administration and from the Department of Defence's website.

\section{Attachment 1(a)}

\section{Plan on a Page}

The intention underlying 'performance management' schemes is well founded where it:

- clarifies individual responsibilities;

- links those to the work of their areas;

- provides a means of regular performance feedback;

- improves openness, transparency and fairness.

We took a different approach from most other departments and agencies. Our approach (based on the government's workplace relations guidelines) endeavours to build performance through a feedback and development focus - without scores and ratings. The military has, of course, had a longstanding performance appraisal system which plays an important role in the promotion and placement of service personnel in a highly planned career management system. 
Our 'Plan on a Page' involves each supervisor and team member agreeing on what needs to be done and what support is required to do this. It establishes the five to seven (no more than nine) objectives that the team member will work towards.

The results-focussed 'Plan on a Page' also identifies learning and development needs. It's important that senior leaders demonstrate their commitment to growth and improvement - to model the way for others.

Australians don't like to fail and they hate letting down anyone they like. So explicit agreement about the learning and development required to get results is a key to 'people power'. It is also about treating people as individuals and helping them work towards their aspirations and potential - to be the best that they can be. The essential question is whether you are learning and growing - whether you're a better person today than last week - rather than how you compare with others.

Supervisors and team members meet quarterly in a two-way feedback process which also reviews progress towards the results and discusses how the team member is developing/improving their performance. If, at the end of the twelve months, the team member has failed to meet their objectives, that also reflects adversely on the supervisor's performance as the coach.

The Chief of the Defence Force and I focussed very hard on the Senior Leadership Group. Our organisational renewal strategy rested on getting involvement and ownership by this group. Unless they themselves changed their day-to-day behaviour, there would always be a rhetoric - reality gap that undermined our efforts to pave the way to real organisational improvement. Behaviour change is hard to achieve, as anyone who has tried to kick a habit knows only too well. The motivation to change behaviour has to come from within - which is why senior leaders who didn't fully 'own' the renewal agenda found it increasingly hard to survive the scrutiny that the Chief of the Defence Force and I were placing on them.

Many Defence leaders were open to feedback, and were working hard at changing their behaviour in an endeavour to treat people as more than just 'human resources'. We were committed to holding our senior leaders just as accountable for stewardship of their people as for delivering the results they are responsible for.

The results of these 'Performance Exchanges' for civilians are linked to remuneration through increment-based advancement until individuals reach the maximum pay point in their pay band. 
The upper limit of the pay band gets adjusted every two years or so when we review our Certified Agreement and Australian Workplace Agreements, having regard to equivalent rates on offer elsewhere in the APS. (The SES AWAs and Certified Agreements were important vehicles for increasing productivity and facilitating the cultural change we were seeking.) Some people argue that this approach penalises the high flyers, because they don't get financial recognition of their superior contribution to the organisation. My retort to this claim is that they are the very people most likely to benefit from accelerated promotion in open merit-based competition.

Money matters, of course. But money does not matter enough to outweigh workplace culture issues. We believe that people want to be paid a fair day's pay for a fair day's work. If people don't feel they're fairly paid, they become dissatisfied. If they do consider they're fairly paid, then we believe they look for other things in the workplace.

The research of an Army Reservist, Brigadier Nick Jans, shows that job satisfaction is a strong predictor of career commitment and the decision to stay in Defence. Leaders can influence job satisfaction through:

- role clarity and focus (do individuals know what they have to do and the contribution they can make?);

- empowerment (do people have the skills, authority and freedom to act while still held responsible for results?);

- teamwork (do others co-operate with and back each other up?);

- learning (can people innovate, learn from doing, take calculated risks and still be supported?).

These factors underpin a high performance culture. They create a work environment where everyone wants to - and can - make a real contribution. 


\title{
Attachment 1(b)
}

\author{
SES Plan on a Page
}

\begin{tabular}{l|l|l}
\hline Employee's Name: & $\begin{array}{l}\text { Supervisor's } \\
\text { Name: }\end{array}$ & $\begin{array}{l}\text { For the forward } \\
\text { period: }\end{array}$ \\
\hline $\begin{array}{l}\text { PART A: Key Expected Results } \\
\text { (KERs) }\end{array}$ & $\begin{array}{l}\text { PART C: Review notes (in terms of } \\
\text { KERS, Values and SES Leadership } \\
\text { Capabilities) }\end{array}$ \\
\hline $\begin{array}{l}\text { 1. Adheres to Defence Values, } \\
\text { demonstrates behaviours consistent with } \\
\text { those values and with Australian Public } \\
\text { Service Values }\end{array}$ & \\
\hline $\begin{array}{l}\text { PART B: Learning and development } \\
\text { needs and actions }\end{array}$ & $\begin{array}{l}\text { PART D: Learning and development } \\
\text { activities undertaken and their } \\
\text { effectiveness }\end{array}$ \\
\hline Employee's Signature: & Date: & \multicolumn{2}{|l}{ Employee's Signature: } & Date: \\
\hline Employee's Signature: & Date: & \multicolumn{3}{|l}{} \\
\hline
\end{tabular}

\section{Attachment 2}

\section{Defence people leadership framework}

\begin{tabular}{|c|c|c|c|}
\hline \multicolumn{4}{|c|}{$\begin{array}{l}\text { To be an effective senior leader in Defence it is implicit that the followi } \\
\text { Defence Values are upheld and promoted: Professionalism, Loyalty, } \\
\text { Innovation, Courage, Integrity, Teamwork }\end{array}$} \\
\hline \multicolumn{4}{|c|}{ PERFORMANCE PRINCIPLE } \\
\hline Challenge & $\begin{array}{l}\text { People like a challenge } \\
\text { and new set performance } \\
\text { standards }\end{array}$ & when & $\begin{array}{l}\text { they are clear about our purpose and } \\
\text { understand where their contribution fits in. }\end{array}$ \\
\hline Elbow-room & $\begin{array}{l}\text { People are responsible, } \\
\text { accountable, exercise } \\
\text { self-direction and self-control }\end{array}$ & when & $\begin{array}{l}\text { their supervisor involves them in } \\
\text { decisions affecting their workplace and } \\
\text { allows them to do their job. }\end{array}$ \\
\hline Feedback & $\begin{array}{l}\text { People exercise imagination, } \\
\text { and creativity to solve } \\
\text { problems }\end{array}$ & when & $\begin{array}{l}\text { they get constructive feedback on their } \\
\text { ideas and are confident that } \\
\text { communication lines are open. }\end{array}$ \\
\hline Self-esteem & $\begin{array}{l}\text { People who feel good about } \\
\text { themselves do good work }\end{array}$ & when & $\begin{array}{l}\text { their supervisor recognises a job well } \\
\text { done - praise from supervisors does } \\
\text { wonders for self esteem. }\end{array}$ \\
\hline Pride & $\begin{array}{l}\text { People are proud of the job } \\
\text { they do and the organisation } \\
\text { they work for }\end{array}$ & when & $\begin{array}{l}\text { the organisation is making a meaningful } \\
\text { contribution to society, engendering } \\
\text { trust and mutual respect. }\end{array}$ \\
\hline
\end{tabular}




\begin{tabular}{|c|c|}
\hline $\begin{array}{l}\text { LEADERSHIP CAPABILITY } \\
\text { Defence leaders: }\end{array}$ & $\begin{array}{l}\text { LEADERSHIP BEHAVIOUR } \\
\text { Defence leaders: }\end{array}$ \\
\hline Set the standard for performance & $\begin{array}{l}\text { 1. Articulate and communicate performance expectations } \\
\text { 2. Explain where people's contribution fits in } \\
\text { 3. Exemplify the standard and encourage/assist others to } \\
\text { perform to the standard } \\
\text { 4. Measure performance and reward/sanction appropriately }\end{array}$ \\
\hline Give meaningful direction & $\begin{array}{l}\text { 1. Involve people in decision-making } \\
\text { 2. Communicate the objective with clarity } \\
\text { 3. Link direction to corporate goals } \\
\text { 4. Ensure people have what they need to get the job done, } \\
\text { within resources allocated }\end{array}$ \\
\hline Make communication a priority & $\begin{array}{l}\text { 1. Tell it as it is } \\
\text { 2. Make sure messages are understood } \\
\text { 3. Listen and respond } \\
\text { 4. Actively create a trusting environment }\end{array}$ \\
\hline Create the climate for success & $\begin{array}{l}\text { 1. Take an interest in people as individuals } \\
\text { 2. Explain people's roles the organisational direction } \\
\text { 3. Value and acknowledge people's contribution } \\
\text { 4. Recognise people by name }\end{array}$ \\
\hline $\begin{array}{l}\text { Persist until the job's well and } \\
\text { truly done }\end{array}$ & $\begin{array}{l}\text { 1. Celebrate the team's achievements } \\
\text { 2. Continually review progress and adjust priorities } \\
\text { 3. Help people understand why the job is important } \\
\text { 4. Understand the resources necessary to complete the tasks }\end{array}$ \\
\hline
\end{tabular}

